Uluslararası Mühendislik

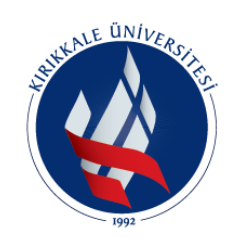

Araştırma ve Geliştirme Dergisi

UMAGD, (2021) 13(3), s202-s214.

FAKÜLTESI

International Journal of

Engineering Research and

$\begin{array}{llcr} & & \text { Development } & 10.29137 / \text { umagd } \\ \text { Cilt/Volume:13 } & \text { Sayı/Issue:3 } & \text { Aralık/December 2021 } & \text { Özel Sayı/ Special Issue }\end{array}$

UMATD, (2021) $13(3)$, s202-s214.

Araştırma Makalesi / Research Paper

\title{
Fotovoltaik Sistemlerde Maksimum Güç Noktası Takibi İçin Değiştir - Gözle, Artan İletkenlik ve Parçacık Sürü Optimizasyon Algoritmalarının Karşılaştırılması
}

\section{Comparison of The Perturb \& Observe, Increased Conductivity and Particle Swarm Optimization Algorithms for Maximum Power Point Tracking in Photovoltaic Systems}

\author{
Murat Lüy1 $^{\text {iD }}$, Fuat Türk ${ }^{2}$ iD, Nuri Alper Metin *3 iD \\ ${ }^{I}$ Kırıkkale Üniversitesi Elektrik-Elektronik Mühendisliği, Kırıkkale, Türkiye \\ ${ }^{2}$ Pursaklar Borsa İstanbul Mesleki ve Teknik Anadolu Lisesi, Ankara, Türkiye \\ ${ }^{3}$ Osmaniye Korkut Ata Üniversitesi, Kadirli Meslek Yüksekokulu, Osmaniye, Türkiye
}

Başvuru/Received: 20/09/2021

Kabul / Accepted: 20/12/2021

Çevrimiçi Basım / Published Online: 31/12/2021

Son Versiyon/Final Version: 31/12/2021

\section{$\ddot{O} \mathbf{z}$}

Artan dünya nüfusuyla birlikte enerji üretimek amacıyla kullanılan petrol ve türevleri ürünlerin azalması, bu ürünlerden atık olarak ortaya çıkan karbon monoksit, metan gazı gibi gazların çevreye verdiği zararı minimum değere indirgemek amacıyla yenilebilir enerji kaynaklarına ilgi artmıştır. Yenilenebilir enerji kaynakları rüzgâr, yakıt hücresi ve güneş panelleri gibi örneklendirilebilir. Yapılan makale çalışmasında güneş paneli sistemlerinde, Doğru Akım (DA) dönüştürücüsü ve Değiştir- Gözle (D\&G), Artan İletkenlik ve Parçacık Sürü Optimizasyonu (PSO) algoritmaları ile Maksimum Güç Noktası Takibi (MGNT) MATLAB/Simulink ortamında tasarlanmış ve değişken ışıma değerlerinde benzetim çalışmaları gerçekleştirilmiştir. Benzetim çalışmaları sonucunda PSO MGNT algoritmasının, D\&G ve Artan İletkenlik algoritmasına göre maksimum güç noktasında değişken ışınım değerlerinde daha az salınım yapmakta olduğu ve maksimumum güç noktasına daha hızlı ulaştığı gözlemlenmiştir.

..

\section{Anahtar Kelimeler}

"Değiş̧tir- Gözle (D\&G) Algoritması, Artan Illetkenlik Algoritması, Parçacı Sürü Optimizasyon (PSO) Algoritması, Maksimum Güç Noktasl Takibi (MGNT)”,

\begin{abstract}
With the increasing world population, the interest in renewable energy sources has increased in order to reduce the decrease in petroleum and its derivatives products used for energy production, and to minimize the damage caused by gases such as carbon monoxide and methane gas, which are produced as waste from these products. Examples of renewable energy sources are wind, fuel cell and solar panels. In the article study, in solar panel systems, Maximum Power Point Tracking (MPPT) with Direct Current (DC) converter and The Perturb \& Observe (P\&O), Increasing Conductivity and Particle Swarm Optimization (PSO) algorithms were designed in MATLAB/Simulink environment and simulation studies at variable radiation values has been carried out. As a result of the simulation studies, it has been observed that the PSO MPPT algorithm oscillates less at the variable radiation values at the maximum power point and reaches the maximum power point faster than the $\mathrm{P} \& \mathrm{O}$ and Increasing Conductivity algorithms.
\end{abstract}

Key Words

"The Perturb \& Observe (P\&O) algorithm, Increased Conductivity algorithm, Particle Swarm Optimization (PSO) algorithm, Maximum Power Point Tracking (MPPT)” 


\section{Giriş}

Günümüzde enerji üretimi artan talepler üzerine hızlı bir gelişim göstermiştir. Enerjinin tanımı gereği yapılması gerekli işin sürecini devam ettirme gücüdür. Enerji, ülkelerin endüstriyel alanda üretim, teknolojinin sürdürebilirliği ve ülkelerin ekonomilerine katkısı açısından önemli bir yere sahiptir. Günümüzde enerji üretiminde yandığında açığa karbondioksit, karbon monoksit ve metan gibi zararlı gazlar çıkaran ve yaygın olarak petrol ve türevlerinin kullanıldığı yakıt türleri kullanılmaktadır. Bu zararlı gazlar hava kirliliği, iklim değiş̧ikliği, asit yağmurları, toprak ve su kirliliğine sebep olmaktadır. Enerji üretiminde kullanılan bu ürünler dünyada bulunan petrol rezervlerinin azalmasına, ülkeler arasında ekonomik açıdan rekabetlerin artmasıyla birlikte petrol ve türevlerinin fiyatlarının yükselmesine sebep olmaktadır (Nazir et al. (2020); Darwesh et al. (2021); Sharif et al. (2021)).

İnsan sağlı̆̆ı ve çevre kirliliğinin artması, enerji üretim sektöründe temiz, verimli ve daha çevreci bir yapıya sahip enerji üretim sistemleri olan yenilenebilir enerji kaynaklarına eğilimi arttırmıştır. Yenilenebilir enerji kaynakları ile belirli bir merkeze bağlı olmadan dağııılmış şekilde enerji üretimi yapılmaktadır. Geleneksel enerji kaynaklarının iletim sağlayamadığı bölgelere de enerji iletimi sağlamaktadır (Nazir et al. (2020); Darwesh et al. (2021); Sharif et al. (2021); Toylan et. al. (2017)).

Yenilenebilir enerji kaynaklarına örnek olarak güneş enerjisi, rüzgâr enerjisi, yakıt hücreleri vb verilebilir. Güneş enerjisi sistemlerinde yüke güç akışı sağlanabilmesi için güneş panellerinden oluşan güç üretim sistemlerinin tasarlanması gerekmektedir. Güneş paneli sistemleri temel olarak güneş 1şı̆̆ındaki foton enerjisinin elektrik enerjisine dönüştürülmesine yarayan, geliştirilmiş, yarı iletken teknolojisidir (Sharif et al. (2021); Toylan et al. (2017); Yıldızay et al. (2014)).

Güneş panelleri yüke doğru akım (DA) gerilim ve akım şeklinde enerji iletimi sağlarlar. Ancak güneş panellerinden üretilen DA gerilim değeri yükün durumuna göre yüksek veya düşükse güç elektroniği devreleri yardımıyla istenen seviyeye getirilmektedir. Güneş enerjisinin gölgelenme, paneldeki kirlenme ve yerleştirilen panellerin güneş ile arasındaki açısı, üretilen gerilim ve akım değerini etkilemektedir. Bu durumların etkisiyle güneş panelinin verimliliği \%20 civarındadır (Toylan et al (2017); Yıldızay et. al. (2014); Turgay et. al. (2016)).

Güneş panellerinin en verimli şekilde kullanılması için geleneksel olarak Değiştir-Gözle (D\&G), Artan İletkenlik, Açık ve Kısa Devre gibi MGNT algoritmaları kullanılmaktadır. Sezgisel algoritmaların MGNT algoritmalarına entegre edilmesiyle alternatif MGNT algoritmaları elde edilebilir (Yıldızay et al. (2014); Turgay et al. (2016)).

\section{Literatür Taraması}

Divyasharon R. ve arkadaşları, güneş paneli, CUK DA dönüştürücü ve yapay sinir ağlarıyla tasarlanmış MGNT algoritmasını içeren bir sistem oluşturmuşlardır. Güneş enerji sistemlerinin verimli kullanılabilmesi ve güneş panellerinin en verimli maksimum güç noktasında çalıştığı için yapay sinir ağları temelli MGNT algoritması geliştirmişlerdir. Benzetim çalışmalarında, değişken hava koşulları göz önüne alınmış olup elde edilen sonuçlara göre yapay sinir ağları geleneksel MGNT algoritmalarından daha yüksek verimli çalıştı̆̆ı gözlemlenmiştir (Divyasharon et al. (2019)).

Dobabi H. ve arkadaşları, son zamanlarda enerji verimliliği ve güneş enerjinin maksimum verimlilikte kullanılabilmesi için birçok MGNT algoritması geliştirmişlerdir. Verimlilik performanslarını etkileyen hava durumları, gölgelenme süreleri ve panel kirliliği, güneş panellerinin enerji üretmesinde büyük zorluklarla neden olmaktadır. Yayınlanan makalede sistem tasarımı olarak güneş paneli, arttıran dönüştürücü ve batarya kullanılmıştır. Arttıran dönüştürünceye anahtarlama sinyali iletimi için Takagi-Sugeno-Bulanık İntegral Hibrit MGNT algoritması tasarlanmıştır. Deney ve benzetim sonuçları elde edilmiş, D\&G, Artan İletkenlik ve D\&G-fractional-order proportional-integral (FOPI) MGNT algoritmalarının sonuçları birbiriyle karşılaştırılmış, tasarlanan MGNT algoritmasının sistemde düşük anahtarlama kayıplarına ve yüksek verimliliğe sahip olduğu gözlemlenmiştir (Dobabi et al. (2021)).

Laxman B. ve arkadaşları, güneş panelli enerji üretim sistemlerinin değişken hava koşullarında maksimum güç noktasında çalışmasının zorluğunu ifade etmişlerdir. Yapılan çalışmada adaptif bulanık mantık denetleyiciyle MGNT tekniği önerilmiştir. Önerilen algoritmada üyelik fonksiyonları Gri Kurt Optimizasyonu ile belirlenmiş ve algoritmanın performansı dört farklı değişken gölgelenme süreleriyle incelenmiştir. Algoritmanın sonuçları klasik D\&G ve bulanık mantık denetleyici algoritmalarının dezavantajlarının üstesinden geldiğini göstermektedir (Laxman et al. (2021)).

Güngör O. Güneş panellerinden alınan verimi arttırmak ve maksimum güç noktasında çalıştırmak için sistem tasarımı olarak CUK doğru akım dönüştürücü, güneş paneli ve üç farklı MGNT algoritması kullanmıştır. Çalışmalarında bulanık mantık denetleyici, yapay sinir ağları ve D\&G MGNT algoritmaları incelenmiş ve performansları benzetim sonuçlarında karşılaştırılmıştır. Klasik D\&G MGNT algoritması, hava koşullarından diğer MGNT algoritmalarından daha az etkilenerek maksimum güç noktasını takip etmiş̧ir (Güngör et al. (2019)).

Keskin Y. ve arkadaşları, güneş paneli, arttıran dönüştürücü D\&G ve Artan İletkenlikMGNT algoritmalarıyla benzetim çalışmasını gerçekleştirmiştir. Sistem, benzetim ve deneysel çalışmaları sonucunda Artan İletkenlik MGNT algoritması, değişken 1şıma 
değerlerinde D\&G algoritmasına göre yük üzerinde gerilim ve akım değerlerinin daha az salınımı gözlemlenmiştir (Keskin et. al. (2014)).

Fathi M. ve arkadaşları, MGNT algoritmalarının güneş panelli enerji üretim sistemlerinin en önemli parçalarından biri olduğunu vurgulayarak, çalışmalarında dört akıllı MGNT algoritması kullanmışlardır Algoritmalar, Bulanık Mantık Denetleyici, Yapay Sinir Ağları tabanlı Genetik Algoritma, Parçacık Sürü Optimizasyonu ve Emperyalist Rekabetçi algoritmalarıdır. Sistemdeki hatalar, ortalama kare hatası ve mutlak hata kullanılarak optimize edilmiştir. Benzetim çalışmaları sonucunda bulanık mantıkla tasarlanan MGNT algoritmasının diğer algoritmalardan daha kararlı ve istikrarlı sonuçlar verdiği gözlemlenmiştir. Yapay sinir ağlarıyla tasarlanan MGNT algoritmasının daha hızlı tepki verdiği, ancak PSO ve genetik algoritmaya göre uygulamada daha karışı olduğu gözlemlenmiş̧ir (Fathi et al. (2021)).

Kumar V. ve arkadaşları, uyarlanabilir yük tabanlı bir MGNT algoritması geliştirmiştir. Çalışmalarında güneş panelinin akım ve gerilim değerini değil de yük gerilimini ölçmeye yarayan tek bir sensör kullanılmıştır. Sistem tasarımında sepic DA dönüştürücüsü güneş panelinin gerilim seviyesini maksimum güç noktası algoritması yardımıyla çıkışa iletmektedir. Tasarlanan MGNT algoritması, D\&G ve Artan İletkenlik algoritmasıyla karşılaştırılmıştır. Tasarlanan sistem deneysel olarak uygulanmıştır (Kumar et al. (2021)).

\section{Sistem Tasarımı}

Sistem, genel olarak güneş paneli, arttıran dönüştürücü, MGNT algoritması ve ohmik yükten oluşan 4 kısımdan oluşmaktadır. Güneş panelinden üretilen doğru gerilim ve akım, arttıran dönüştürücü girişine uygulanır. Arttıran dönüştürücüye MGNT algoritmasından elde edilen görev oranı, üçgen dalga ile karşılaştırılarak S anahtarına PWM dalgası üretilir ve istenen seviyede ohmik yük üzerinden gerilim ve akım değeri elde edilir. Sistemin genel şeması Şekil 1'de gösterilmiştir.

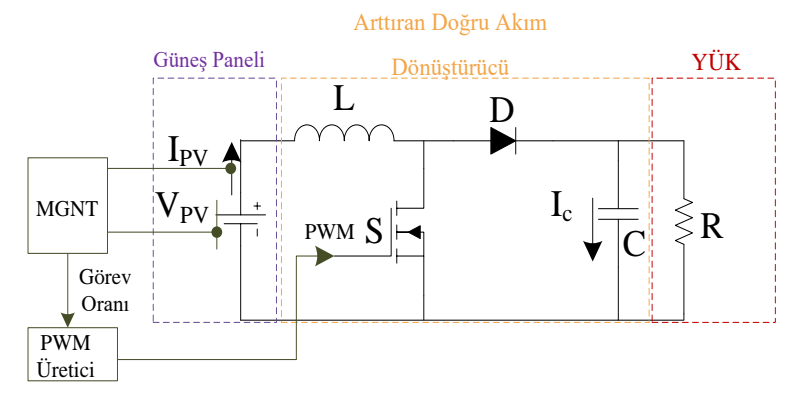

Şekil 1. Sistem Şeması

\section{Güneș Paneli Matematiksel Modeli}

Güneş paneli modülleri temel olarak P-N eklemlemelerinin birbirleriyle olan bağlantısını içermektedir. Şekil-2’ de güneş panelinin basit elektriksel eş değer devresi gösterilmiştir. Şekil güneş paneli modülü akımı (IPV), ters paralel diyot akımı (Id), yarı iletken malzemelerin direncini temsil eden seri direnci (Rs) ve P-N ekleminden akan kaçak akımın neden olduğu kayıpları temsil eden şönt (Rp) direncini içermektedir (Zafar et al. (2021); Dobabi et al. (2021)).

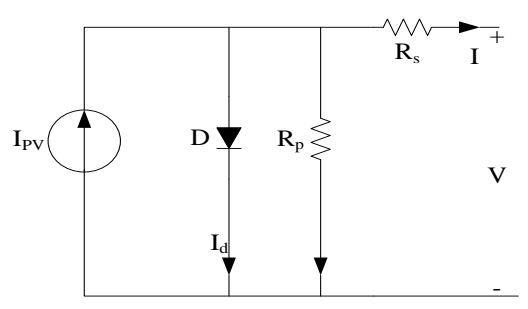

Şekil 2. Güneş panel modülünün elektriksel eş değer devresi

Şekil-2'de gösterilen güneş paneli modülünün elektriksel eşdeğer devresinin akım ve gerilim eşitlikleri Denklem 1'de verilmiştir.

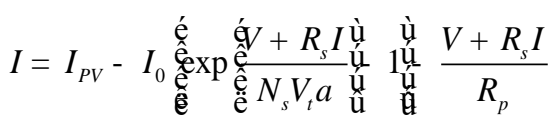

Burada V güneş paneli modülü çıkış gerilimi ve I güneş paneli modülü çıkış akımıdır. IPV ve I0, sırasıyla güneş paneli modülü akımı ve doyma akımıdır. Vt=kT/q olarak tanımlanır ve güneş paneli modülünün termal gerilimidir. Burada $\mathrm{q}$ bir elektron yükü, $\mathrm{k}$ boltzman 
sabiti, T kelvin cinsinden bağlantı sıcaklık derecesidir. A diyotun ideallik sabitidir. Güneş paneli modülünün ürettiği enerji sadece matematiksel denkleme bağlı olmayıp sıcaklık, güneş ışığının geliş derecesi ve ışıma gibi faktörlere de bağlıdır. Işıma ve sıcaklık değerlerine bağlı olarak değişim Eşitlik (2), Eşitlik (3) ve Eşitlik (4)'te verilmiştir (Zafar et al. (2021); Dobabi et al. (2021)).

$$
\begin{aligned}
& I_{P V}=I_{P V, n}+K_{I}\left(T-T_{n}\right) \frac{G}{G_{n}} \\
& V_{o c}=V_{o c, n}+K_{V}\left(T-T_{n}\right)
\end{aligned}
$$

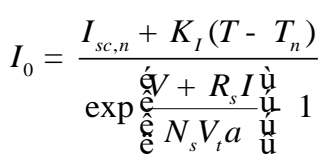

\section{Arttıran DA-DA Dönüştürücü}

Dönüştürücüler giriş ile çıkış arasında istenen eşitliği sağlamak amacıyla tasarlanan devre elemanlarıdır. Dönüştürücülerde temel kural giriş gücüyle çıkış gücünün aynı değerde olmasıdır. İstenen çıkış gerilimi, giriş geriliminden yüksekse, giriş gerilimi yükseltilerek çıkışa iletilir. Bu durumda giriş akımı değeri azalarak çıkışa iletilir. Bu tip dönüştürücülere Arttıran Dönüştürücü adı verilmektedir (Dobabi et al. (2021); Pradhan et al. (2018)).

Dönüştürücü tasarımı yapılırken tasarım önemli bir yere sahiptir. Bobinin değerine göre sistem sürekli ve süreksiz modda çalışmaktadır. Bobin değeri hesaplanan tasarım değerinden düşük seçilirse sistem süreksiz modda çalışır ve bobin üzerindeki akım belirli zaman aralıklarında sıfıra düşer. Bobin değeri tasarım değerinden yüksek seçilirse sistem sürekli modda çalışır. Bobin üzerindeki akım sıfıra düşmez. Süreksiz mod, çalışmak istenen bir çalışma modu değildir. Çünkü yarı iletken malzemelerde ani sıcaklık yükselmesi ve kayıplarda artış meydana gelmektedir (Dobabi et al. (2021); Pradhan et. al. (2018)).

Devre tasarımında istenen, yolların kesitinin büyük olmamasıdır. Sürekli çalışma modunda süreksiz çalışma moduna nazaran yarı iletken malzemelerin ısınması azdır ve devre tasarımında yolların kesitleri kü̧̈üktür. Dönüştürücülerin giriş ve çıkışı arasındaki ilişki anahtarlama elemanının açık ve kapalı konumuna göre belirlenir. (Dobabi et al. (2021); Pradhan et al. (2018)).

Sistemde arttıran dönüştürücü incelenecektir. Arttıran dönüştürücü devre yapısı olarak anahtar(S), güç aktarım diyotu (D), enerji depolama elemanlarından (L, C) oluşmaktadır. Burada bobin (L) enerji depolayarak giriş ve çıkış arasındaki ilişkiyi düzenlerken, kondansatör (C) çıkıştaki gerilim dalgalanma oranını düzenlemektedir. Arttıran dönüştürücü devre yapısı Şekil 3'te görülmektedir.

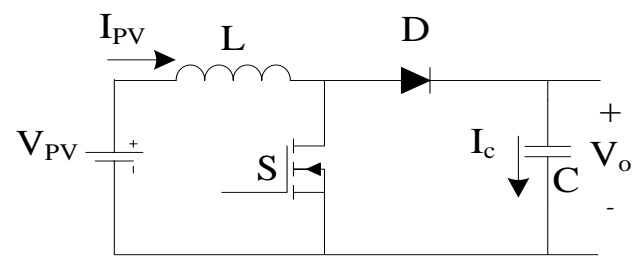

Şekil 3. Arttıran DA dönüştürücü devre yapısı

Dönüştürücülerde giriş ve çıkış arasındaki iletim, anahtarın (S) iletim ve kesimde olma durumlarının incelenmesiyle belirlenir. Anahtar iletimdeyken, bobin batarya akımıyla üzerinde enerji depolar. Üzerindeki gerilim değeri batarya gerilimine eşittir. Diyot doğru yönde kutuplanmadığı için iletime geçmez. Bu durum Şekil 4'te gösterilmiştir (Pradhan et al. (2018)).

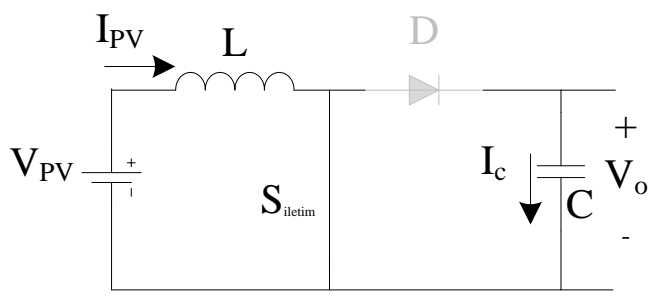

Şekil 4 Anahtarın iletim durumu

Bobin gerilim eşitliğinde D ile gösterilen görev oranı olup 0 ile 1 arasında değişim göstermektedir. Denklem 5 'te verilmiştir.

$\frac{d i_{L}}{d t}=\left(V_{b a t}\right) \times D$ 
Anahtar kesimdeyken. bobin üzerindeki gerilim değeri batarya gerilimiyle, çıkış geriliminin farkına eşittir. Diyot doğru yönde kutuplanır ve iletime geçer. Bu durum Şekil 5’te gösterilmiştir [16].

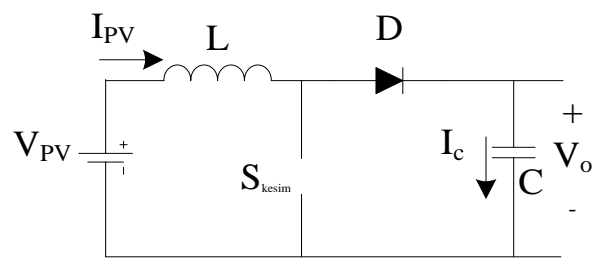

Şekil 5. Anahtarın kesim durumu

Bobin gerilim eşitliği Eşitlik (6)'da verilmiştir.

$\frac{d i_{L}}{d t}=\frac{\left(V_{b a t}-V_{C}\right)}{L} \times(1-D)$

Eşitlik (5) ve (6)'dan giriş ve çıkış arasındaki ilişki Eşitlik (7) elde edilmiştir.

$V_{C}=\frac{V_{b a t}}{(1-D)}$

Görev oranı (D) 0 ile 1 arasında olduğundan DA dönüştürücüde çıkış gerilim değeri giriş gerilim değerinden yüksek olmaktadır.

\section{Maksimum Güç Noktası Takip Algoritmaları}

Güneş panelleri 1şıma ve sıcaklık faktörlerine bağlı olarak DA gerilim ve akım üretirler. Güneş panelinin güç, gerilim eğrisinde maksimum güç noktası adı verilen tek bir nokta vardır. Sistemin çalışmasında MGNT algoritmaları DA dönüştürücünün güneş paneli ile yük arasındaki güç akışını sağlar. MGNT algoritmaları, güneş panelini maksimum güç noktasında çalıştırmak için tasarlanır. DA dönüştürücülerin anahtarlama elemanlarına maksimum güç noktası için görev oranını belirler ve PWM sinyali belirlenen görev oranına göre üretilir (Sher et al. (2015); Harrag et al. (2019)).

\subsection{D\&G (Değiştir ve Gözle) MGNT Algoritması}

$D \& G$ algoritması anahtarlama süresince uygulanır. $D \& G$ algoritmasındaki amaç çıkış gücünü optimum değerde tutmaktır. Bu durumda ilk olarak güneş panelinden anlık olarak gerilim ve akım değerleri okunur. İkincil olarak okunan akım ve gerilim değerlerinden güç hesaplanır. Güç hesaplaması sonucunda hesaplanan güç değeri bir önceki güç değeriyle karşılaş̧ırıllır. Gerilim azaldığında güçte azalır, bu durumda çalışma noktası maksimum güç noktasının solunda bulunurken, tam tersi durumda sağında bulunmaktadır. D\&G MGNT algoritması, güneş panelinin çıkışının maksimum güç noktasına ulaşılıncaya kadar tekrarlanır. Sistem maksimum güç noktasına ulaştığında salınım yapmaya başlar. D\&G MGNT akış şeması Şekil-6' da verilmiştir (Selmi et. al. 2014; Hamidon et al. (2012); Kollimalla et al. (2013)).

\subsection{Artan İletkenlik MGNT Algoritması}

Güneş enerjisi sistemi için güneş paneli gücünün güneş paneli gerilimine göre türevi Eşitlik (8)'de verilmiştir (Patel et. al. 2017; Keskin et al. (2012)).

$$
\frac{d P}{d V}=\frac{d(I V)}{d V}=I+V \frac{d I}{d V}
$$

Artan İletkenlik MGNT algoritmasında temel olarak güneş panelinin güç gerilim eğrisinin eğimine bakılır. Eğer eğim pozitifse maksimum güç noktasının solunu, negatifse sağını eğim sıfıra eşitse maksimum güç noktasını göstermektedir. Eşitlik (8) verilen bilgilere göre çözülürse; maksimum güç noktasında bulunduğu durum Eşitlik (9)'da verilmiştir (Patel et al. (2017); Keskin et. al. (2012)).

$\frac{d I}{d V}=\frac{-I}{V}$ 


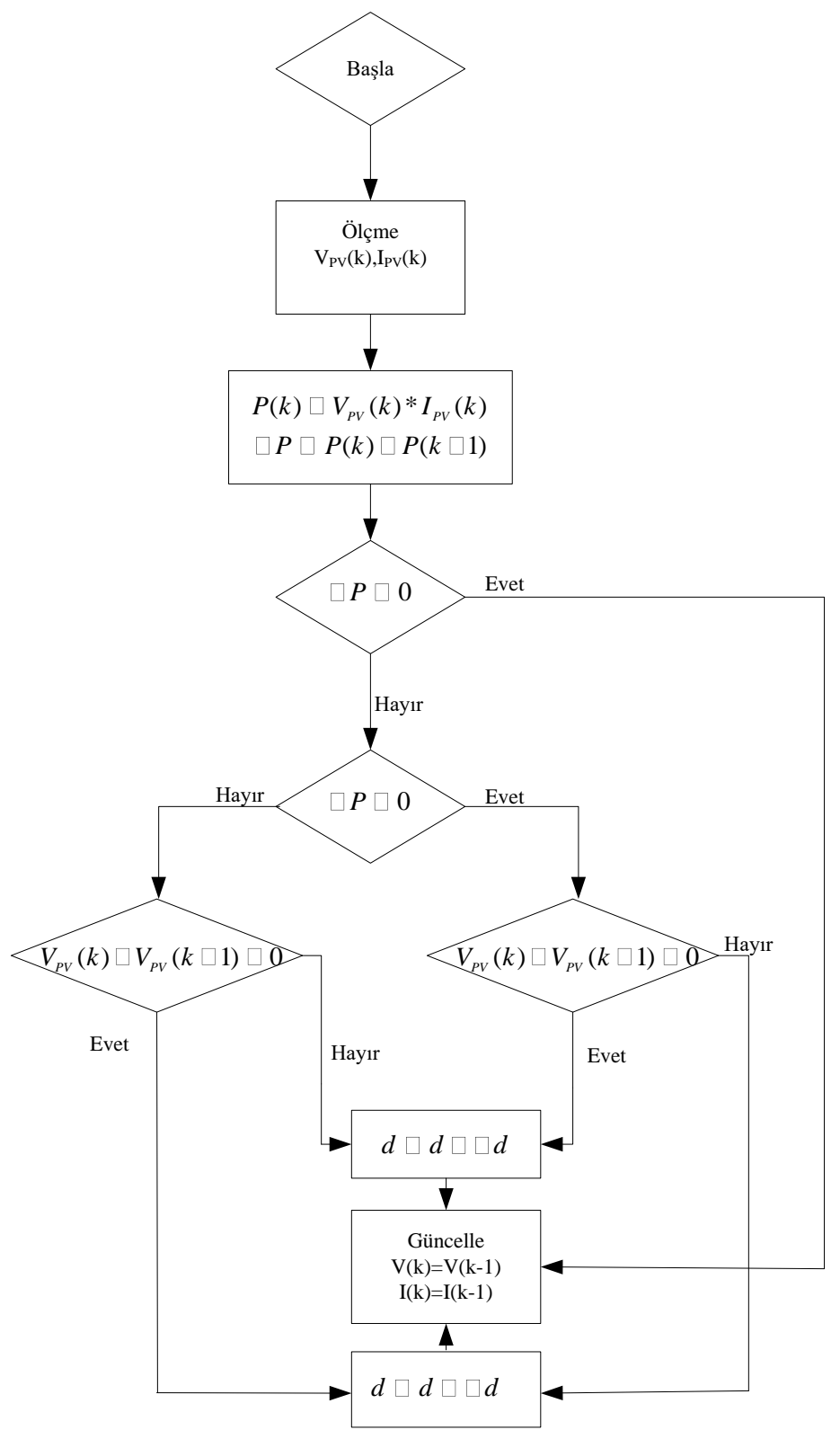

Şekil 6. D\&G MGNT algoritması akış şeması

Maksimum güç noktasının solunda bulunduğu durum Eşitlik (10)'da verilmiş̧ir.

$$
\frac{d I}{d V}>\frac{-I}{V}
$$

Maksimum güç noktasının solunda bulunduğu durum Eşitlik (11)'de verilmiştir.

$$
\frac{d I}{d V}<\frac{-I}{V}
$$

Artan İletkenlik MGNT algoritması akış şeması Şekil 7'de verilmiştir. 


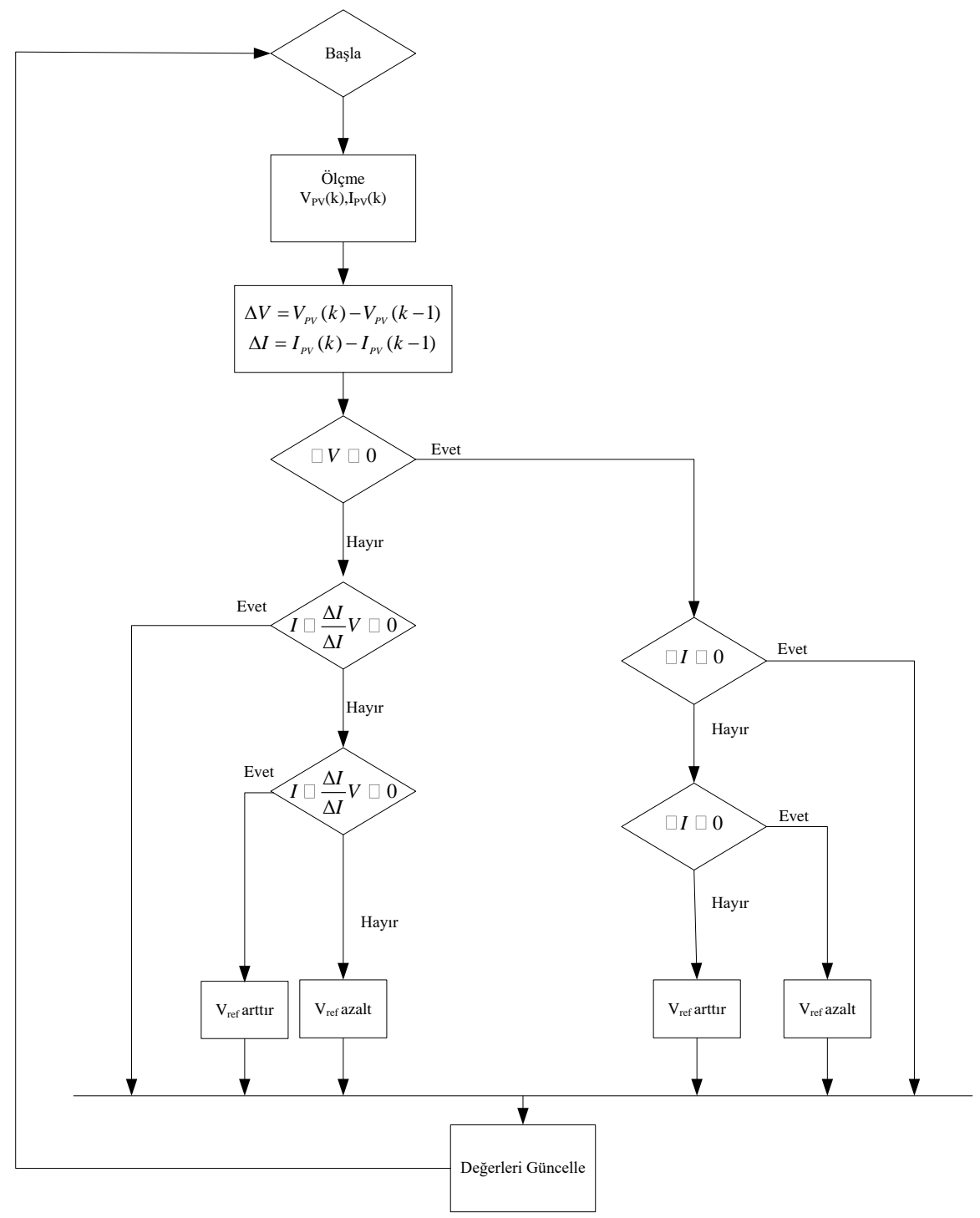

Şekil 7. Artan İletkenlik MGNT algoritması akış şeması

\subsection{PSO MGNT Algoritması}

PSO, 1995 yılında Eberhart ve Kennedy tarafından teorik olarak akıllı optimizasyon tekniği olarak geliştirilmiştir. Algoritmanın temelinde sürü şeklinde gezen kuş, balık gibi hayvanların doğal davranışlarından esinlenilmiştir. PSO algoritmasında uçan kuşların gideceği yerin haritalanması ve ağırlık değişkenlerinden yararlanılmıştır. Grup üyelerinin her bir üyesinden sırasıyla bilgiler alınarak en optimize değere ulaşılır. PSO parçacık olarak adlandırılan bireyler arasında sosyal davranışları kullanarak arama uzayında bireyleri adaptif olarak en anlamlı kısma yönlendirmektedir. PSO algoritması, ilk olarak tanımlanan problemin çözümü için rastgele cevaplar ile başlatılır. Bu rastgele değerler güncellenerek en uygun çözüm aranır. Her iterasyon işlemi sonucunda parçacık lokasyonları en iyi iki parçacığa göre güncellenir. PSO algoritmasının akış şeması Şekil-8'de gösterilmiştir (Mahapatra et al. (2019); Shi et al. (2015); Gümüş et al. (2021)).

PSO algoritmasında parçacıklar çok boyutlu arama uzayına dağıtılır. Dă̆ıtım esnasında her parçacık rastgele konumlarını kendi deneyim sonuçlarına göre ayarlar, ayarlanan bu değere parçacıkların şimdiye kadar ulaştı̆̆ı en iyi çözüm denir. Komşu parçacığın deneyimine göre kendisinin ve komşusunun güncel değerlerinin karşılaştırılmasıyla elde edilen değer, iterasyon sırasında elde edilen en iyi değer olarak isimlendirilir. Parçacıkların hızı Eşitlik (12) ve konumu Eşitlik (13)'e göre güncellenir (Mahapatra et al. (2019); Shi et al. (2015); Gümüş et al. (2021)).

$$
\begin{aligned}
\mathrm{V}_{i}^{k} & =\mathrm{w}_{i} \cdot \mathrm{V}_{i}^{k}+\mathrm{c}_{1} \cdot \operatorname{rand}() \cdot\left(\mathrm{P}_{\text {best } i}^{k}-\mathrm{X}_{i}^{k}\right)++\mathrm{c} 2 \cdot \operatorname{rand}() \cdot\left(\mathrm{G}_{\text {best } i}{ }^{k}-\mathrm{X}^{k}{ }_{i}\right) \\
\mathrm{X}^{k}{ }_{i} & =\mathrm{X}^{k}{ }_{i}+V^{k}{ }_{i}
\end{aligned}
$$




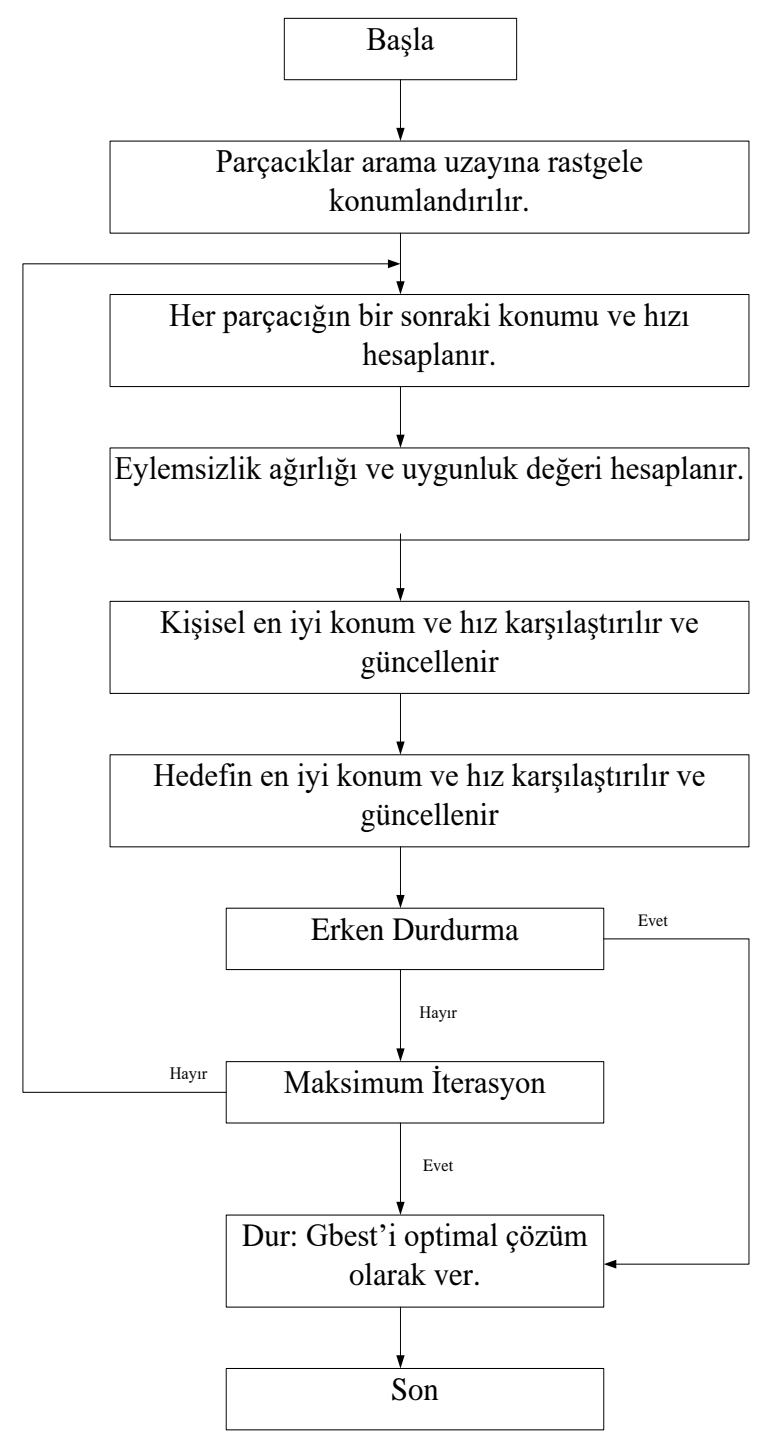

Şekil 8. PSO akış şeması

Genel olarak MGNT algoritmalarındaki asıl amaç maksimum güç noktasını bulmaktır. PSO algoritmasında giriş olarak güneş panelinin akım ve değerleri alınır. Alınan bu değerlerin çarpımıyla panelin gücü elde edilir. Elde edilen güç değeri ile bir önceki güç değeri arasındaki farka göre PSO MGNT algoritmasında belirlenen referansa göre görev oranı değeri, iterasyon sayısına göre tekrar güncellenir. Sistem içerisinde parçacıkların global ve yerel büyüklerinde elde edilen en yüksek güç, sistemin maksimum güç noktasının o parçacığın yeri olduğunu göstermektedir. Arttıran dönüştürücü için PSO MGNT algoritmasından görev oranı çıkışı alınır ve yük üzerine istenen gerilim ve akım değeri alınır (Mahapatra et al. (2019); Shi et al. (2015); Gümüş et al. (2021)).

\section{Benzetim Sonuçları}

Bu çalışmada değişken 1şıma değerlerine göre D\&G, Artan İletkenlik ve PSO MGNT algoritmalarıyla maksimum güç noktası takibi yapılmıştır. Sistemde panel gücü ve yük üzerinden alınan güç değerleri, değişken ışıma değerlerinde incelenmiştir. Panel ve çıkış gücünden yararlanarak D\&G, Artan İletkenlik ve PSO MGNT algoritmaları, maksimum güç ulaşım süresi ve maksimum güç noktasını takibi açısından karşılaştırma işlemi gerçekleştirilmiştir Sistem tasarımı MATLAB/Simulink ortamında gerçekleştirilmiştir. Sistemin MATLAB/Simulink devre şeması Şekil 9' da verilmiştir. 


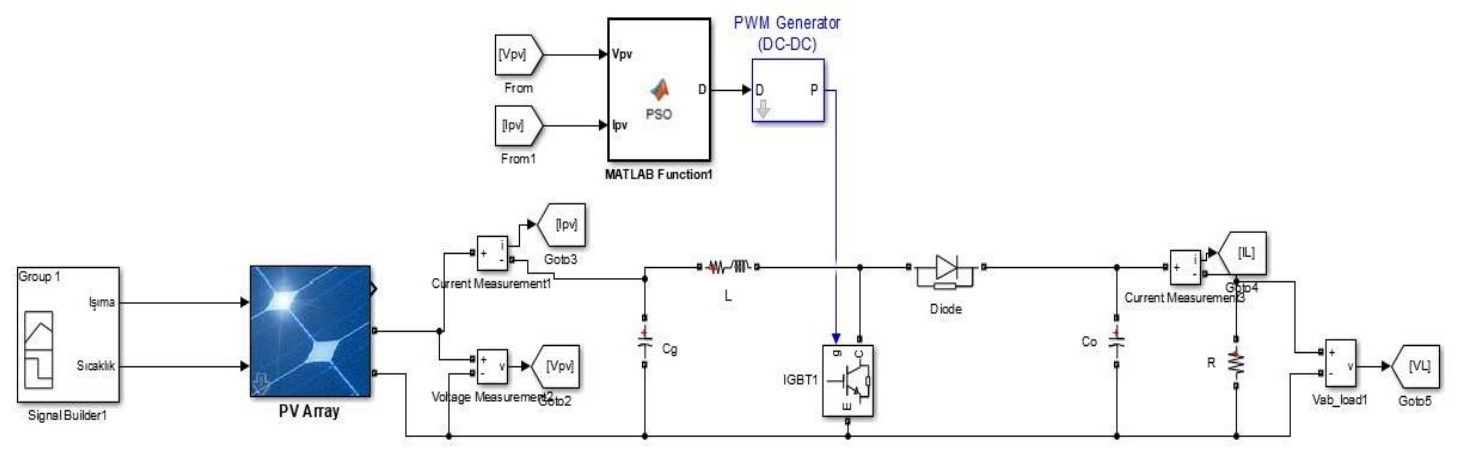

Şekil 9. Sistemin MATLAB/Simulink Devre Şeması

Güneş paneli tasarımı 5 adet seri ve 66 adet paralel modülün birbirine bağlantısı ile gerçekleştirilerek elde edilmiştir. Panel parametreleri 1 modül için Tablo 1'de verilmiştir.

Tablo 1. Sun Power SPR-205-WHT Güneş Panelinin Modül Başına Parametreleri

\begin{tabular}{lccc}
\hline Parametre Adı & Sembol Adı & Değeri & Birimi \\
\hline Maksimum Güç & $\mathrm{P}_{\text {maks }}$ & 96 & Watt (W) \\
Açık Devre Gerilimi & $\mathrm{V}_{\mathrm{oc}}$ & 64.2 & Volt (V) \\
Maksimum Güçteki Gerilim & $\mathrm{V}_{\mathrm{mp}}$ & 54.7 & Volt (V) \\
Kısa Devre Akımı & $\mathrm{I}_{\mathrm{sc}}$ & 5.96 & Amper (A) \\
Maksimum Güçteki Akım & $\mathrm{I}_{\mathrm{mp}}$ & 5.58 & Amper (A) \\
\hline
\end{tabular}

Güneş panelinin sabit sıcaklıkta, değişken ışınım değerlerine maksimum güç noktası, akım ve gerilim eğrisi Şekil 10'da gösterilmiştir.
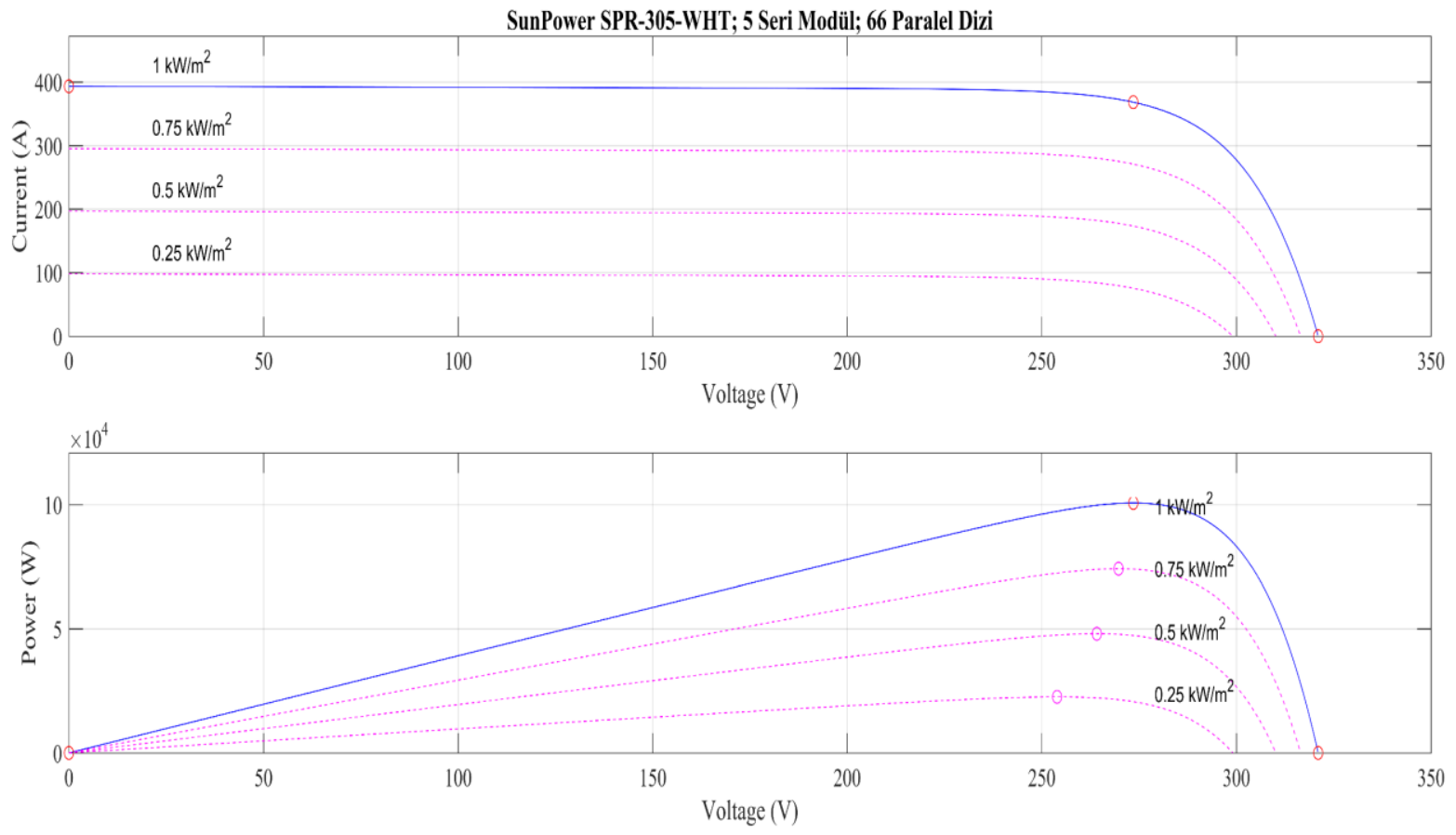

Şekil 10. Güneş panelinin sabit sıcaklıkta, değişken ışınım değerlerine maksimum güç noktası, akım ve gerilim eğrisi

Sistem içerisindeki kısmi gölgelendirmelerin test edilebilmesi ve çıkıştaki yük üzerinde kararlı güç değeri elde edilmesi açısından güneş paneli ile yük arasına arttıran DA dönüştürücü güç elektroniği devre yapısı kullanılmıştır. Arttıran dönüştürücün devre parametreleri ve anahtarlama frekansı Tablo 2'de verilmiştir. 
Tablo 2 Arttıran Dönüştürücü Devre Parametreleri

\begin{tabular}{lccc}
\hline Parametre Adı & Sembol Adı & Değeri & Birimi \\
\hline Bobin & $\mathrm{L}$ & 5 & Milihenry $(\mathrm{mH})$ \\
Giriş Kondansatörü & $\mathrm{C}_{\mathrm{in}}$ & 100 & Mikrofarad (uF) \\
Çıkış Kondansatörü & $\mathrm{C}_{\mathrm{o}}$ & 12 & Milifarad (mF) \\
Yük & $\mathrm{R}$ & 3 & Ohm \\
Anahtarlama Frekansı & $\mathrm{f}_{\mathrm{s}}$ & 5000 & $\mathrm{~Hz}$ \\
\hline
\end{tabular}

Güneş paneline 2 saniye aralıklarla değişken olarak uygulanan ışıma ve sabit 25 oC sıcaklık değerleri Şekil 11'de gösterilmiştir.

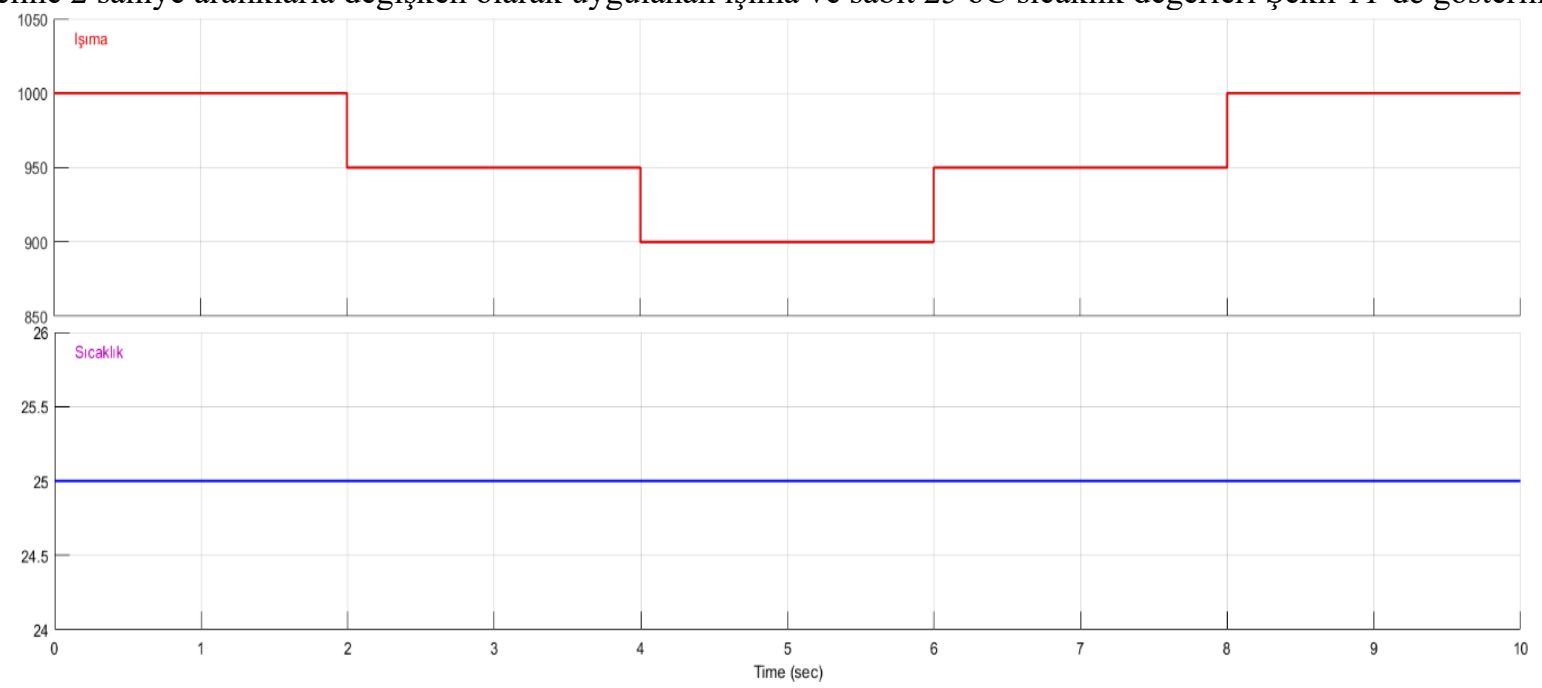

Şekil 11. Güneş paneline uygulanan 1şıma ve sıcaklık değerleri

Bu çalışmada kullanılan D\&G, Artan İletkenlik ve PSO MGNT algoritmaları tasarımında değişken ışıma değerlerinde çıkış güçleri elde edilmiştir. PSO parametreleri Tablo 3’te verilmiştir.

Tablo 3. PSO MGNT algoritması parametreleri

\begin{tabular}{cc}
\hline Ă̆ırlık (w) & $\mathbf{0 . 1 1}$ \\
\hline $\mathrm{c} 1=\mathrm{c} 2$ & 0.9 \\
\hline
\end{tabular}

Gözle ve değiştir, Artan İletkenlik ve PSO MGNT algoritmalarının panel ve yük üzerindeki güç Şekil 12’de gösterilmiştir. 


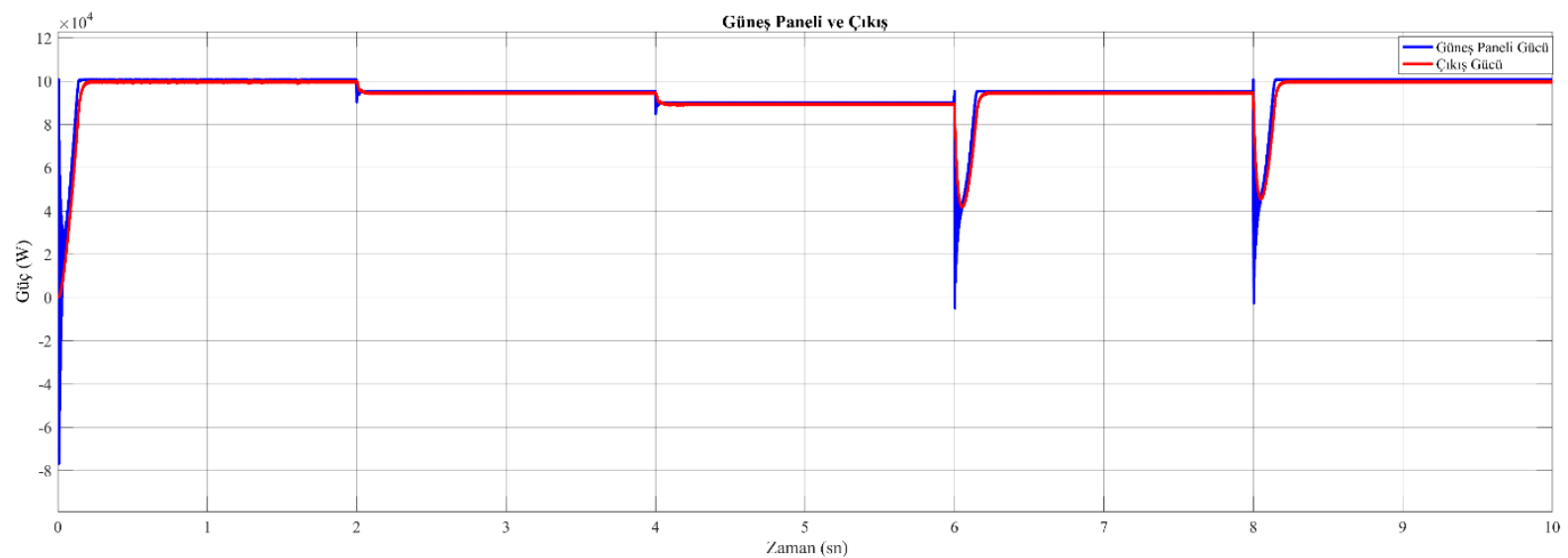

(a)

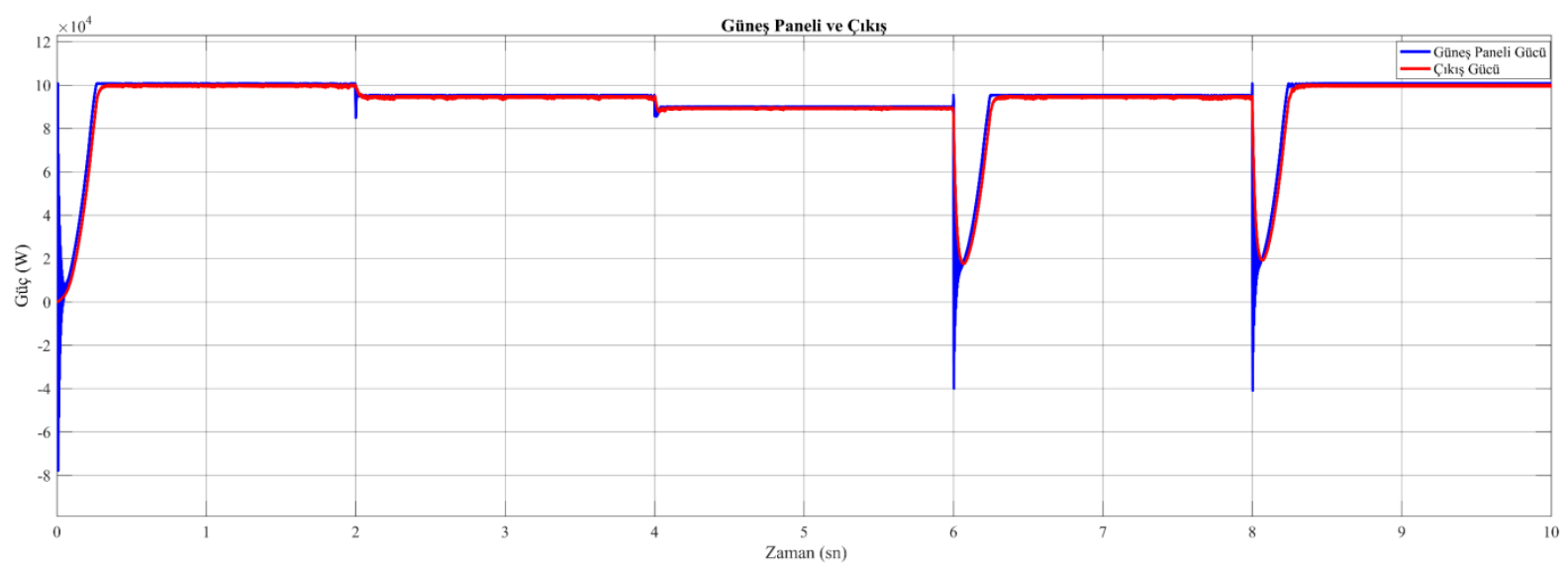

(b)

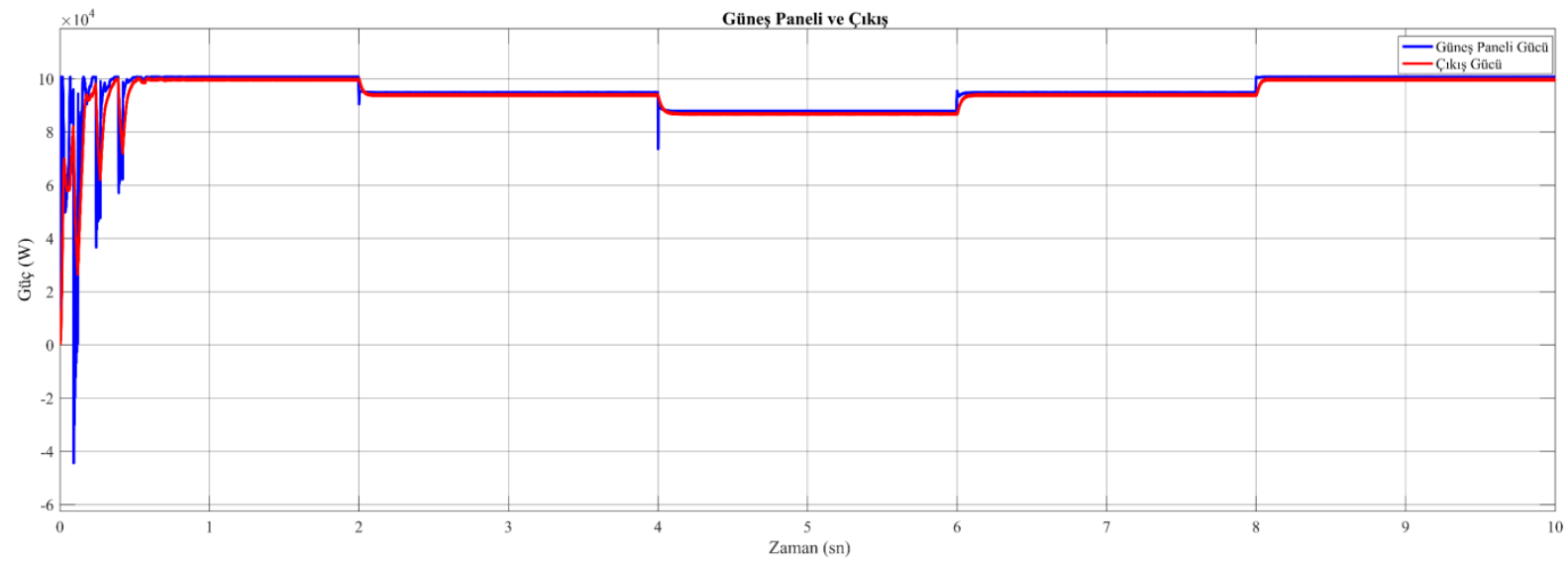

(c)

Şekil 12. a) Değiştir ve Gözle b) Artan İletkenlik c) PSO MGNT Algoritmaları Güneş Paneli ve Çıkış Gücü

\section{Sonuç ve Tartışma}

Yapılan makale çalışmasında güneş panellerinde değişken ışıma değerlerinde maksimum güç noktası değerlerine en yakın değerde sonuç elde etmek için MATLAB/Simulink ortamında D\&G, artan iletkenlik, PSO ile MGNT algoritmaları ile benzetim çalışması gerçekleştirilmiştir. Benzetim çalışmaları sonucunda D\&G MGNT algoritması Artan İletkenlik ve PSO MGNT algoritmalarına göre 
maksimum güç noktasında salınım değerlerinin fazla olduğu gözlemlenmiştir. Artan İletkenlik MGNT algoritmasında değişken ışınım değerlerinde maksimum güç noktası değerine ulaşım süresi ve güçteki genlik değişiminin yüksek olduğu gözlemlenmiştir. Parçacık sürü optimizasyonu, sistemin ilk çalışma anında maksimum güç noktasına ulaşmasında diğer algoritmalara göre yavaş takip süresi gerçekleştirmiş olsa bile, maksimum güç noktasında salınım değerleri ve ışınım değişimlerine daha stabil ve kararlı tepki verdiği gözlemlenmiştir.

\section{Referanslar}

Darwesh, M. R., \& Ghoname, M. S. (2021). Experimental studies on the contribution of solar energy as a source for heating biogas digestion units. Energy Reports, 7, 1657-1671.

Divyasharon, R., Banu, R. N., \& Devaraj, D. (2019). Artificial neural network based MPPT with CUK converter topology for PV systems under varying climatic conditions. In 2019 IEEE International Conference on Intelligent Techniques in Control, Optimization and Signal Processing (INCOS) (pp. 1-6). IEEE.

Doubabi, H., Salhi, I., Chennani, M., \& Essounbouli, N. (2021). High Performance MPPT based on TS Fuzzy-integral backstepping control for PV system under rapid varying irradiance-Experimental validation. ISA transactions.

Fathi, M., \& Parian, J. A. (2021). Intelligent MPPT for photovoltaic panels using a novel fuzzy logic and artificial neural networks based on evolutionary algorithms. Energy Reports, 7, 1338-1348.

Gümüş, Z., \& Demirtaş, M. (2021). Fotovoltaik Sistemlerde Maksimum Güç Noktası Takibinde Kullanılan Algoritmaların Kısmi Gölgeleme Koşulları Altında Karşılaştırılması. Politeknik Dergisi, 1-1.

Güngör, O. (2019). Güneş Panellerinde Cuk Dönüştürücü Tabanlı Değişken Şartlar Altında PNO, BM ve YSA Algoritmalarının Karşılaştırmalı Performans Analizi. Bilecik Şeyh Edebali Üniversitesi Fen Bilimleri Dergisi, 6(1), 66-76.

Hamidon, F. Z., Aziz, P. A., \& Yunus, N. M. (2012). Photovoltaic array modelling with P\&O MPPT algorithm in MATLAB. In 2012 International Conference on Statistics in Science, Business and Engineering (ICSSBE) (pp. 1-5). IEEE.

Harrag, A., Messalti, S., \& Daili, Y. (2019). Innovative single sensor neural network PV MPPT. In 2019 6th International Conference on Control, Decision and Information Technologies (CoDIT) (pp. 1895-1899). IEEE.

Keskin, Y. E., Başoğlu, M. E., Tekdemir, İ. G., \& Çakır, B. (2014). Fotovoltaik Sistemlerde D\&G ve Artan İletkenlik Algoritmalarının Karşılaştırılması Comparison of $\mathrm{P} \& \mathrm{O}$ and Incremental Conductance Algorithms for Photovoltaic Systems.

Kollimalla, S. K., \& Mishra, M. K. (2013). Novel adaptive P\&O MPPT algorithm for photovoltaic system considering sudden changes in weather condition. In 2013 International Conference on Clean Electrical Power (ICCEP) (pp. 653-658). IEEE.

Kumar, V., Ghosh, S., Naidu, N. S., Kamal, S., Saket, R. K., \& Nagar, S. K. (2021). Load voltage-based MPPT technique for standalone PV systems using adaptive step. International Journal of Electrical Power \& Energy Systems, 128, 106732.

Laxman, B., Annamraju, A., \& Srikanth, N. V. (2021). A grey wolf optimized fuzzy logic based MPPT for shaded solar photovoltaic systems in microgrids. International Journal of Hydrogen Energy, 46(18), 10653-10665.

Mahapatra, S., Badi, M., \& Raj, S. (2019). Implementation of PSO, it's variants and Hybrid GWO-PSO for improving Reactive Power Planning. In 2019 Global Conference for Advancement in Technology (GCAT) (pp. 1-6). IEEE.

Nazir, M. S., Abdalla, A. N., Wang, Y., Chu, Z., Jie, J., Tian, P., ... \& Tang, Y. (2020). Optimization configuration of energy storage capacity based on the microgrid reliable output power. Journal of Energy Storage, 32, 101866.

Patel, A., \& Tiwari, H. (2017). Implementation of INC-PIMPPT and its comparison with INC MPPT by direct duty cycle control for solar photovoltaics employing zeta converter. In 2017 International Conference on Information, Communication, Instrumentation and Control (ICICIC) (pp. 1-6). IEEE.

Pradhan, A., \& Panda, B. (2018). A simplified design and modeling of boost converter for photovoltaic sytem. International Journal of Electrical and Computer Engineering, 8(1), 141.

Selmi, T., Abdul-Niby, M., Devis, L., \& Davis, A. (2014). P\&O mppt implementation using matlab/simulink. In 2014 Ninth International Conference on Ecological Vehicles and Renewable Energies (EVER) (pp. 1-4). IEEE. 
Sharif, A., Meo, M. S., Chowdhury, M. A. F., \& Sohag, K. (2021). Role of solar energy in reducing ecological footprints: An empirical analysis. Journal of Cleaner Production, 292, 126028.

Sher, H. A., Murtaza, A. F., Noman, A., Addoweesh, K. E., Al-Haddad, K., \& Chiaberge, M. (2015). A new sensorless hybrid MPPT algorithm based on fractional short-circuit current measurement and P\&O MPPT. IEEE Transactions on sustainable energy, 6(4), 14261434.

Shi, J., Zhang, W., Zhang, Y., Xue, F., \& Yang, T. (2015). MPPT for PV systems based on a dormant PSO algorithm. Electric Power Systems Research, 123, 100-107.

Toylan, H., \& HÜNER, E. (2017). Uyarlamalı Sinirsel Bulanık Çıkarım (ANFIS) Tabanlı Güneş Takip Sistemi. Afyon Kocatepe Üniversitesi Fen ve Mühendislik Bilimleri Dergisi, 17(2), 546-554.

Turgay, K. A. Y. A., \& GÜLER, H. (2016) Güneş Takip Sistemlerinde Maksimum Çıkış Gerilimi için Bulanık-Genetik Algoritma Tabanlı Sistem Tasarımı. Fırat Üniversitesi Mühendislik Bilimleri Dergisi, 28(2), 99-108.

Yıldızay, H. D., Haydar, A. R. A. S., \& YILMAZ, V. (2014). Eskişehir'de rüzgâr ve güneş enerjisi potansiyelinin belirlenmesi. Dicle Üniversitesi Mühendislik Fakültesi Mühendislik Dergisi, 5(1), 49-58.

Zafar, M. H., Khan, N. M., Mirza, A. F., Mansoor, M., Akhtar, N., Qadir, M. U., ... \& Moosavi, S. K. R. (2021). A novel meta-heuristic optimization algorithm based MPPT control technique for PV systems under complex partial shading condition. Sustainable Energy Technologies and Assessments, 47, 101367. 